Farum

Sociológico

\section{Forum Sociológico}

Série II

31 | 2017

Transition to work of graduates in Southern Europe:

Crisis and new challenges

\title{
Nota acerca do Seminário Internacional Como apoiar pessoas refugiadas : abordagens e iniciativas de trabalho voluntário na Europa, Lisboa, 9 de Junho de 2017
}

Vicente Valentim, Inês Vieira e Christine Auer

\section{OpenEdition \\ Journals}

Edição electrónica

URL: https://journals.openedition.org/sociologico/1790

DOI: 10.4000/sociologico. 1790

ISSN: 2182-7427

Editora

CICS.NOVA - Centro Interdisciplinar de Ciências Sociais da Universidade Nova de Lisboa

\section{Refêrencia eletrónica}

Vicente Valentim, Inês Vieira e Christine Auer, «Nota acerca do Seminário Internacional Como apoiar pessoas refugiadas : abordagens e iniciativas de trabalho voluntário na Europa, Lisboa, 9 de Junho de 2017», Forum Sociológico [Online], 31 | 2017, posto online no dia 11 maio 2018, consultado o 30 março 2022. URL: http://journals.openedition.org/sociologico/1790 ; DOI: https://doi.org/10.4000/ sociologico. 1790 


\title{
NOTA ACERCA DO SEMINÁRIO INTERNACIONAL COMO APOIAR PESSOAS REFUGIADAS: ABORDAGENS E INICIATIVAS DE TRABALHO VOLUNTÁRIO NA EUROPA, LISBOA, 9 DE JUNHO DE 2017
}

\author{
Vicente Valentim \\ European University Institute \\ Inês Vieira \\ Universidade Nova de Lisboa, Faculdade de Ciências Sociais e Humanas, Centro Interdisciplinar de Ciências Sociais \\ (CICS.NOVA) \\ Christine Auer \\ Fundação Friedrich Ebert
}

A Fundação Friedrich Ebert Portugal, em conjunto com a European Alternatives, organizaram no dia 09.06.2017, no Goethe-Institut Lisboa, um seminário dedicado a discutir a situação dos refugiados e das organizações da sociedade civil que Ihes prestam apoio em Portugal, em diálogo com outras experiências europeias. Este relatório tem como objetivo sumariar os principais pontos discutidos, que são do interesse geral não só para compreender o atual debate em torno da questão em Portugal, mas também para estimular o trabalho voluntário e a reflexividade em torno do tema ${ }^{1}$. 0 evento incluiu duas mesas-redondas e um world café, com discussões em pequenos grupos. Os autores participaram no evento como organizadores e dinamizadores.

A primeira mesa-redonda discutiu o trabalho voluntário para e com os refugiados, com particular foco nas especificidades do caso português. Os participantes partilharam a experiência que adquiriram oferecendo assistência humanitária a refugiados e trabalhando para a sua integração.

Tola Akindipe, cofundador do Refugees Welcome Portugal $^{2}$, discutiu a sua perspetiva acerca do trabalho voluntário em geral e os passos que têm vindo a ser tomados pela sua associação na integração dos refugiados. Defendeu que, idealmente, o trabalho voluntário envolveria algum conhecimento e compreensão do que implica ser um refugiado. Argumentou também ser vital possuir um conhecimento básico do contexto legal humanitário, a nível doméstico, europeu e internacional, bem como reconhecer os seus próprios limites - de ordem emocional e em termos de disponibilidade.

Francisco Font Bell, da União de Refugiados em Portugal (UREP) ${ }^{3}$, partilhou um testemunho muito pessoal do que para ele significa ser refugiado. A sua própria experiência, de quando veio de Cuba para Portugal, há 12 anos, e a falta de assistência com que então se deparou motivaram-no a fazer trabalho voluntário como forma de contribuir para cobrir essa lacuna. Foi com este objetivo que, em 2016, nasceu a UREP, que tem como missão apoiar os refugiados no exercício da cidadania através da mediação intercultural. Bell descreveu típicos problemas quotidianos e barreiras que impedem a integração, principalmente de ordem administrativa, expondo a discrepância existente entre a legislação em vigor e a situação real enfrentada pelos refugiados.

Rui Tavares, membro da European Alternatives ${ }^{4}$ e antigo deputado europeu, defendeu que a Europa não enfrenta uma crise de refugiados, mas antes uma crise de coordenação. Fez referência à Declaração Universal dos Direitos Humanos das Nações Unidas (1948), lamentando o seu caráter não-vinculativo. Dado que a proteção dos direitos humanos básicos consagrados nesta carta é da responsabilidade de cada Estado, Tavares referiu dois cenários possíveis para os garantir: uma ação proativa do Estado quando confrontado com violações dos direitos humanos no seu território; um compromisso com uma "agenda radical de direitos humanos" por parte dos cidadãos e da sociedade civil, na ausência de ações por parte do Estado.

No que diz respeito a experiências de integração sustentável de refugiados, Akindipe mencionou a importância de se explorarem as áreas de especialização dos voluntários, lamentando o reduzido reconhecimento dado a atividades de voluntariado, situação que deve ser revertida para que se possibilite a construção de uma sociedade civil ativa. Akindipe argumentou também que o envolvimento entre voluntários e refugiados é um processo recí- 
proco, que contribui para quebras de estereótipos e diversificação dos atores envolvidos. Enfatizou também a importância das interações entre refugiados e comunidades migrantes já estabelecidas no país de acolhimento, como forma de contribuir para uma melhor integração dos primeiros.

Pela sua parte, Bell apelou à necessidade de encarar os refugiados como seres humanos, parando de os reduzir a números, vagas ou crises. Focou também o facto de as leis migratórias e de asilo portuguesas estarem entre as mais favoráveis da Europa, valendo ao país elogios no plano internacional pela sua abertura e permissividade; porém, a rigidez administrativa verificada no terreno acaba por minar o processo de integração. Relativamente ao trabalho voluntário, Bell referiu a indispensabilidade da acessibilidade de informação acerca do que significa o trabalho voluntário, das formas através das quais se pode ajudar e da ajuda que já está a ser providenciada aos refugiados. Criticou também o défice de representação dos refugiados nos processos de tomada de decisões políticas.

No que diz respeito ao apoio e integração de refugiados, Tavares sumarizou a situação portuguesa como uma de boas intenções que acabam sendo goradas pela falta de organização. Uma forma possível de colmatar estas falhas seria o desenvolvimento de iniciativas na área de especialização de cada um. Assim, encorajou a audiência a apresentar projetos, por exemplo recorrendo a planos de financiamento da UE.

Todos os intervenientes concordaram na necessidade de criação de um Conselho de Refugiados em Portugal, dado que o Serviço de Estrangeiros e Fronteiras, que atualmente lidera a ação em matéria de refugiados, age basicamente como uma entidade policial. Seguidamente os organizadores apresentaram o "World Café", convidando os participantes a discutir um conjunto de assuntos em pequenos grupos. Atribuindo a mesma relevância às visões, opiniões e experiências de todos os participantes no seminário, este formato permitiu contrabalançar as discussões mais especializadas das mesas-redondas. Durante o decorrer do world café, os participantes eram livres de circular entre os seis grupos de discussão temática.

O primeiro grupo tinha como tema "Quero voluntariar-me, que posso fazer?". Nenhum dos participantes neste grupo tinha experiência prévia de voluntariado, mas todos estavam dispostos a adquiri-la, apesar de se encontrarem inseguros acerca do que fazer. Muitos procuravam uma organização que os pudesse ajudar respondendo às suas dúvidas e divulgando oportunidades de voluntariado. O grupo debruçou-se também sobre a questão das qualificações dos voluntários. Apesar de certas profissões terem particular capacidade de oferecer ajuda direta e de a proficiência linguística ser essencial para este tipo de trabalho, focou-se a possibilidade de desempenhar atividades voluntárias que não carecem de qualificações específicas e a importância de cada um seguir a sua vocação pessoal.

Um segundo grupo dedicou-se aos desafios que se apresentam ao trabalho voluntário. Neste grupo, os participantes tinham já uma ideia concreta de como pretendiam voluntariar-se, alguns tendo até já adquirido alguma experiência de voluntariado. Entre os desafios do trabalho voluntário sobre os quais este grupo se debruçou contaram-se a questão do financiamento dos voluntários, tendo sido discutidas oportunidades de financiamento na UE, bem como as dificuldades sentidas em contactar organismos governamentais e administrativos. Os participantes também sublinharam a necessidade de saber qual a melhor forma de abordar os refugiados e de fazer esforços no sentido de os projetos voluntários corresponderem a necessidades concretas da população refugiada.

O terceiro tema, "Partilhando boas práticas", atraiu um grande número de participantes com experiência prévia de trabalho voluntário. Os mais experientes referiram-se a áreas específicas nas quais creem ser necessário um maior desenvolvimento: o apoio à integração linguística; a comunicação e criação de redes de instituições de apoio; a provisão de cuidados de saúde dignos aos refugiados; campanhas de informação que preparem os voluntários para a vulnerabilidade da situação de muitos refugiados; e a passagem de ações imediatas a estratégias de longo prazo. Os participantes discutiram também vários modelos inovadores que podem ser mais explorados: o uso do teatro como forma de lidar com traumas; o reforço do papel de mediadores culturais e linguísticos; a transmissão da experiência dos refugiados aos decisores políticos; o reforço da colaboração com as estruturas existentes que têm experiência de trabalho com recém-chegados; a organização de festivais para imigrantes e refugiados, à semelhança do ImigrArte ${ }^{5}$; e a necessidade de criação de redes que liguem as várias iniciativas de apoio aos refugiados numa dada cidade.

O quarto grupo discutiu o tópico "Apoio aos refugiados baseado na sociedade civil vs. baseado no Estado". Muitos participantes consideraram este apoio como sendo uma competência da sociedade civil, dada a capacidade das suas organizações de agir de forma mais concreta e direta. Ainda assim, alguns participantes defenderam que o Estado poderia desempenhar o importante papel de apoiar iniciativas do terceiro setor, particularmente através de medidas que permitissem a manutenção de apoio voluntário contínuo à integração dos refugiados. Os participantes referiram também a ausência de participação dos refugiados nas organizações da sociedade civil e os limites estruturais à implementação de políticas e leis como fragilidades das instituições 
do terceiro setor. Foram propostos dois modelos para colmatar as falhas do Estado em assegurar o acesso dos refugiados ao sistema de providência: um Conselho Internacional de Refugiados; e um comissário eleito pelas instituições que trabalham com refugiados, operando ao nível local. Houve também referências a exemplos positivos de cooperação entre Estado e organizações da sociedade civil, como o programa de Mentores para Migrantes ${ }^{6}$ do Alto Comissariado para as Migrações.

Um quinto grupo discutiu "Voluntariado centrado nos refugiados". Defenderam-se as potencialidades de cursos de treino para voluntários, como o que é oferecido pela Plataforma de Apoio aos Refugiados $(P A R)^{7}$. O conhecimento de como abordar, proteger e lidar com diferentes situações foi considerado crucial para lidar com questões de género, bem como para trabalhar com pessoas em situação de grande vulnerabilidade, como indivíduos traumatizados ou vítimas de violência. Alguns participantes deste grupo consideraram que o Estado devia ter mais responsabilidades em áreas relacionadas com os refugiados que careçam de trabalho especializado, como no acesso a cuidados médicos. Outros argumentaram que o trabalho voluntário deveria antes ter lugar fora das instituições, o que levaria voluntários e refugiados a entrar em contacto com novas pessoas e participar em atividades de lazer. O grupo discutiu também a necessidade de superar o risco de manipulação do tema dos refugiados pelos media.

Por último, um sexto grupo dedicou-se ao tema "Assistência de emergência vs. integração dos refugiados". Nele, os participantes sublinharam a existência de uma certa ambiguidade na integração dos refugiados na sociedade portuguesa. Por um lado, as políticas do país em matéria de migrações são alvo de frequentes elogios por parte da comunidade internacional, fruto da sua reputação de inclusividade e permissividade. No entanto, a integração dos refugiados acaba sendo minada por barreiras administrativas e pela falta de empatia nas instituições estatais. Os participantes relataram várias instâncias de aplicações incorretas da legislação em vigor, de desresponsabilização do Estado na provisão de direitos mínimos dos refugiados e de falta de assistência no acesso ao sistema de providência. Foi também considerado essencial que se tenha em conta a opinião dos próprios migrantes e refugiados no seu processo de integração.

A segunda mesa-redonda dedicou-se a exemplos de voluntariado em três cidades: Berlim, Roma e Lisboa. Andreas Tölke, da Be an Angel ${ }^{8}$, relatou como a sua associação e a sua cidade, Berlim, acolheram centenas de pessoas e trabalharam com firmas de advogados para combater injustiças legais de que os refugiados eram vítimas. O próprio Tölke acolheu cerca de 600 refugiados em sua casa. Este orador colocou uma forte ênfase na necessidade de criar empatia com os refugiados, estabelecendo ligações reais com eles.

Felix Eikenberg, da Friedrich-Ebert-Stiftung Forum Berlin ${ }^{9}$, ofereceu um panorama geral de como o município de Berlim lidou com o grande número de refugiados que chegaram à cidade a partir do verão de 2015, argumentando que a cidade passou por duas fases distintas. A primeira durou do verão de 2015 até à primavera de 2016 e correspondeu ao período em que um grande número de pessoas chegava diariamente a Berlim, dificultando a resolução até das necessidades básicas mais prementes, dado o subfinanciamento das organizações que as deviam endereçar. A partir da primavera de 2016, a situação tornou-se algo mais moderada, permitindo que os desafios se movessem das necessidades humanas mais básicas para outras considerações, como a necessidade de melhorar as condições dos abrigos dos refugiados.

Andrea Costa, da Baobab Experience ${ }^{10}$, apresentou a situação de Roma, onde a sua associação atua. Na ausência de um plano para lidar com o influxo de refugiados, a cidade assistiu à chegada de um grande número de pessoas que, na sua maioria, eram migrantes em trânsito que procuravam chegar aos países do Norte da Europa, pelo que as forças policiais italianas nada podiam ou estavam dispostas a fazer acerca da sua situação. Tal deu origem a uma grande vaga de apoio por parte dos habitantes de Roma, que procuraram resolver algumas das necessidades mais prementes dos recém-chegados. A Baobab foi criada com esse objetivo, durante este período.

Jessica Lopes, da Solidariedade Imigrante ${ }^{11}$, enfatizou que Portugal não tem um número muito alto de refugiados, mas antes de migrantes não documentados. Posteriormente, apresentou a sua associação, que trabalha defendendo os direitos dos imigrantes num conjunto de áreas, ao mesmo tempo que promove a sua inserção na sociedade portuguesa. É uma associação composta unicamente de ativistas, onde mesmo as pessoas que vêm à procura de ajuda são encorajadas a tornar-se membros.

Cristina Santinho, antropóloga e investigadora do Centro em Rede de Investigação em Antropologia (CRIA-IUL), também sublinhou as diferenças entre o debate político em torno dos refugiados em Portugal - no qual há uma tendência para os partidos concordarem na necessidade de acolher os recém-chegados e promover a sua inserção na sociedade - e a forma como estes são realmente tratados, enfrentando inúmeras dificuldades, principalmente na fase da sua integração na sociedade. Para colmatar estas falhas, a sua instituição, o ISCTE-IUL, criou o curso "Viver numa Cultura Diferente"12, que oferece aos refugiados ferramentas que Ihes permitem integrarem-se mais facilmente 
na cultura portuguesa, funcionando também como um primeiro passo para o reconhecimento das suas habilitações académicas.

No debate que se seguiu à exposição inicial dos oradores, Andreas Tölke sublinhou a importância de se estar aberto a debater com pessoas que tenham perspetivas diferentes, como forma de combater a islamofobia e a xenofobia. Felix Eikenberg referiu-se à política do medo que o partido alemão AfD tenta criar. No entanto, referiu que a maioria da população alemã é positiva ou neutra acerca do tema das migrações. Jessica Lopes corroborou o argumento já avançado segundo o qual o problema de Portugal é o de haver um discurso público demasiado otimista, que dificulta responder os problemas que persistem.

A sessão abriu então para questões da audiência. Durante a discussão que se Ihe seguiu, houve intenso debate em torno das características que foram atribuídas a um "bom voluntário". Santinho argumentou que só é possível ajudar depois de se conhecer profundamente a situação dos recém-chegados, sendo a empatia, por si só, insuficiente. Já Andreas Tölke defendeu que a empatia é a mais importante característica de que se necessita para fazer voluntariado, dela decorrendo naturalmente tudo o resto.

Este foi um evento esporádico e fica em aberto até que ponto conseguirá oferecer um impulso rele- vante para a criação de um debate nacional acerca do apoio aos refugiados ou inspirar a atividade dos voluntários com as suas ideias. De qualquer forma, permitiu sem dúvida que o trabalho voluntário em Portugal granjeasse reconhecimento público.

\section{Notas}

1 Tendo em conta este objetivo e o enquadramento do debate à escala internacional, este documento será publicado noutras línguas em revistas estrangeiras.

2 Website: http://www.refugees-welcome.net.

3 Página Facebook: https://www.facebook.com/urep.pt/.

${ }^{4}$ Website: https://euroalter.com.

${ }^{5}$ Website: http://www.festival-imigrarte.com.

${ }^{6}$ Website: https://mentores.acm.gov.pt/home.

7 Website: http://www.refugiados.pt.

8 Website: http://beanangel.direct.

${ }^{9}$ Website: http://www.fes-forumberlin.de.

10 Website: https://baobabexperience.org/.

${ }^{11}$ Website: www.solimigrante.org/.

12 Mais informações sobre esta iniciativa-piloto em https:// www.iscte-iul.pt/noticias/1224/iniciativapiloto-curso-gratuito-para-integracao-de-refugiados-no-ensino-superior (consulta 01/08/2017).

Recebido a 03/08/2017. Aceite para publicação a 09/11/2017.

Vicente Valentim (vicente.valentim@eui.eu). European University Institute. Via della Badia dei Roccettini, 9, 50014 Fiesole FI, Itália.

Inês Vieira (ines.vieira@fcsh.unl.pt). Universidade Nova de Lisboa, Faculdade de Ciências Sociais e Humanas, Centro Interdisciplinar de Ciências Sociais (CICS.NOVA). Edifício I\&D, Avenida de Berna, 26-C, 1069-061 Lisboa, Portugal.

Christine Auer (auer@fes-portugal.org). Fundação Friedrich Ebert, Avenida Sidónio Pais, 16, 1. Dto, 1050-215 Lisboa, Portugal. 